\title{
Are there gross motor coordination spurts during mid-childhood?
}

\author{
Marcos A. M. dos Santos ${ }^{1,2}$ (1) ～Adam Baxter-Jones ${ }^{3}$ । Ana C. Reyes ${ }^{2}$ । \\ Duarte Freitas $^{2,4}$ | Rafael S. Henrique ${ }^{1}$ () । Raquel N. Chaves ${ }^{5}$ । \\ Alcibíades Bustamante ${ }^{2,6}$ ～Go Tani ${ }^{7}$ | Peter T. Katzmarzyk ${ }^{8}$ । José Maia
}

\begin{abstract}
${ }^{1}$ Department of Physical Education, University of Pernambuco, Recife, Brazil

${ }^{2} \mathrm{CIFI}^{2} \mathrm{D}$, Kinanthropometry Lab, Faculty of Sport, University of Porto, Porto, Portugal

${ }^{3}$ College of Kinesiology, University of Saskatchewan, Saskatoon, Canada

${ }^{4}$ Department of Physical Education and Sport, University of Madeira, Funchal, Portugal

${ }^{5}$ Department of Physical Education, Federal University of Technology-Parana' (UTFPR), Curitiba, Brazil

${ }^{6}$ National University of Education Enrique Guzmán e Valle, Lima, Peru

${ }^{7}$ School of Physical Education and Sport, University of São Paulo, São Paulo, Brazil

${ }^{8}$ Pennington Biomedical Research Center, Louisiana State University, Baton Rouge, Louisiana
\end{abstract}

\section{Correspondence}

Marcos A. M. dos Santos, Physical

Education School, University of

Pernambuco. Arnóbio Marques street, 310.

Santo Amaro, 50100-130-Recife, PE, Brazil.

Email: mmoura23@gmail.com

\begin{abstract}
Objectives: The aims of this study were (1) to identify the timing of the midgrowth spurt (MGS) in stature in children and (2) to identify gross motor coordination (GMC) spurts when aligned by the age of attainment of the MGS (aMGS).

Methods: Stature, weight, and GMC were measured in 245 Portuguese children followed annually from 6 to 10 years. GMC was assessed and to estimate children's MGS in stature as well as GMC spurts in each of the four tests aligned by aMGS, we used a nonsmoothed polynomial methodology.

Results: In boys, the aMGS was attained at 7.8 years, whereas in girls it was 8.0 years. In boys, the peak MGS was $6.2 \mathrm{~cm} \cdot \mathrm{yr}^{-1}$ and in girls it was $6.4 \mathrm{~cm} \cdot \mathrm{yr}^{-1}$. In boys, the peak for walking backwards (WB) occurred 18 months before aMGS (14.9-points $\mathrm{yr}^{-1}$ ), jumping sideways (JS) was 12 months after aMGS (13.5-points· $\mathrm{yr}^{-1}$ ), hopping on one leg (HO) was 18 months before aMGS (11.7-points. $\mathrm{yr}^{-1}$ ), and shifting platform (SP) was 12 months before aMGS (6.8-points· $\mathrm{yr}^{-1}$ ). In girls, WB spurts occurred 12 months after aMGS (13.3-points.yr ${ }^{-1}$ ), JS was 12 months before aMGS (10.5-points $\left.\cdot \mathrm{yr}^{-1}\right)$, HO was coincident with aMGS (10.4-points· $\mathrm{yr}^{-1}$ ), and SP was 18 as well as 12 months before aMGS (7.2-points. $\mathrm{yr}^{-1}$ ). No differences were observed in the mean peak spurts between sexes in the GMC tests.

Conclusions: Boys and girls reached their MGS in stature at about the same chronological age. Spurts in GMC did not express themselves in the same biological timing relative to aMGS in stature, and there are sex differences.
\end{abstract}

\section{1 | INTRODUCTION}

During adolescence there is an intense spurt in growth of stature (peak height velocity, PHV), and sex differences are observed in relation to the timing of PHV that occurs, on average, 2 years earlier in girls $(\sim 12$ years $)$ than in boys ( 14 years) (Gasser, Sheehy, Molinari, \& Largo, 2001; Hauspie \& Roelants, 2012). It has also been shown that there are peaks in motor performance (MP) during adolescence and that the timing and tempo of such peaks are task- and sex-specific. Their occurrence has been aligned in relation to the age of attainment of PHV (Beunen \& Malina, 1988).
However, the adolescent growth spurt is not a single phenomenon, since another smaller peak occurs earlier in midchildhood, between 6 and 8 years of age, and termed the mid-growth spurt (MGS) (Butler, McKie, \& Ratcliffe, 1990; Gasser et al., 1985; Molinari, Largo, \& Prader, 1980). Since MP and motor coordination are linked with PHV, it seems reasonable to assume that they will also be interconnected with the MGS in stature.

Since girls, on average, are approximately 2 years more advanced in maturity than boys at a given age, that is, closer to the mature state, it has been suggested that the use of a biological age marker rather than chronological age should 
be used to interpret MP change dynamics (Beunen \& Malina, 1988). Using such methodology enhances the possibility of identifying MP spurts in a variety of motor domains that are otherwise impossible to detect when data are aligned by chronological age. As far as we know, there is no such information on GMC, especially because there are no longitudinal data sets that embrace the whole adolescent growth period. However, serial GMC data covering the childhood period, namely from 6 to 9 years of age, exist (Maia et al., 2007). Moreover, as Mühl, Herkner, and Swoboda (1992) and Lejarraga (2012) suggested, based on consistent growth and hormonal data, the MGS could be considered a biological marker within the biological development of a child, in the same way that age at PHV has been used. Linking MP and GMC to the mid-childhood growth spurt is important in educational/pedagogical terms because the MGS shows individual differences in both its initiation and duration. This is important since accelerated growth may affect children's control of their body's movements, and they may require some time to adapt. It is thus possible that MGS differences influence GMC spurts affecting children's overall MP in a variety of their daily tasks. These issues become even more relevant because it has been pointed out that children's motor development has also been associated with health-related habits and behaviors (Robinson et al., 2015). It is known that the interval from 6 to 9 years is sensitive for the refinement of a variety of fundamental movement skills and that development of health-enhanced behaviors may persist into adolescence (Gallahue, Ozmun, \& Goodway, 2012). It has also been suggested that GMC and MP interact synergistically (Stodden et al., 2008) and are associated with healthenhancing physical activity behaviors during childhood and throughout adolescence (Barnett et al., 2016; Gallahue et al., 2012). Therefore, the purpose of this study is twofold: (a) to identify the timing of the MGS spurt stature in children of both sexes, and (b) to identify GMC spurts when performance is aligned to the age of attainment of the MGS in stature.

\section{2 | METHODS}

\section{1 | Participants}

Subjects were selected from a mixed-longitudinal study on growth, physical activity, gross motor coordination (GMC), physical fitness, biological maturation, body composition, and motivation for sport conducted in Azorean youth (Maia et al., 2007). In brief, subjects from four main Azores Islands (Faial, Pico, São Miguel, and Terceira), Portugal, were randomly selected. To avoid seasonal variation, all measurements were taken annually in the fall by trained physical education teachers from each participating school. The objectives and procedures of the study were thoroughly explained to parents and their informed consent was obtained. The Azorean Government Board of Education and the Government Directorate of Sports approved the study, and it was ethically approved by the Faculty of Sport, University of Porto.

The study was initiated in 2002, and the last wave of data collection was in 2007. Children from the first cohort were observed initially at 6 years of age (ie, in 2002) and were followed annually from 6 to 10 years (primary school). Dropout was insignificant, $<10 \%$, and no systematic differences were found between those who remained in the study (complete data) and those with missing data. Since GMC was only assessed in children followed consecutively from 6 to 9 years of age, in the present study only those with complete serial data were selected, and 245 children fulfilled this requirement. Age was used as decimals of a year and children aged 5.5 to 6.49 years were designated as $6,6.50$ to 7.49 years as 7 , and so on.

\section{2 | Anthropometry}

All body measurements were made according to standard protocols (Lohman, Roche, \& Martorell, 1988). Stature was measured using a portable stadiometer (Siber Hegner, Switzerland) to the nearest $0.5 \mathrm{~cm}$ with children measured with their feet together and head in the Frankfurt plane. Body mass was measured to the nearest $0.1 \mathrm{~kg}$ on a Seca scale (Seca Optima 760 , Germany) with children lightly dressed and barefoot.

\section{3 | Gross motor coordination}

Children GMC was assessed with a standard test battery developed in Germany (Körperkoordinationtest für Kinder [KTK]) by Schilling and Kiphard (1974) and published in English by Willimczik (1980). There has been a recent upsurge of KTK use in different countries such as Belgium (Vandorpe et al., 2011), Brazil (Gorla, de Araújo, \& Rodrigues, 2010), Mozambique (Tchamo, Moura-dos-Santos, dos Santos, Prista, \& Leandro, 2017), Portugal (Antunes et al., 2016; Chaves et al., 2015), and Peru (Valdivia et al., 2008, 2008), demonstrating its widespread applicability.

The KTK comprises the following tests: (a) walking backwards (WB) - the child walks backward on a balance beam $3 \mathrm{~m}$ in length, with a progressive reduction of widths $(6 \mathrm{~cm}$, $4.5 \mathrm{~cm}$, and $3 \mathrm{~cm}$ ); (b) jumping sideways (JS) — the child makes consecutive jumps from side to side over a small beam $(60 \mathrm{~cm} \times 4 \mathrm{~cm} \times 2 \mathrm{~cm})$ as fast as possible for 15 seconds; (c) hopping on one leg (HO) over an obstacle-the child is instructed to hop on one foot at a time over a stack of foam squares; after a successful hop with each foot, the height is increased by adding a square $(50 \mathrm{~cm} \times 20 \mathrm{~cm} \times 5 \mathrm{~cm})$; and (d) shifting platform (SP)—-the child begins by standing with 
both feet on one platform $(25 \mathrm{~cm} \times 25 \mathrm{~cm} \times 2 \mathrm{~cm}$ supported on four legs $3.7 \mathrm{~cm} \mathrm{high),} \mathrm{places} \mathrm{the} \mathrm{second} \mathrm{platform} \mathrm{alongside}$ the first and steps on to it, the first platform is then placed alongside the second and the child steps on to it, the sequence continues for 20 seconds. The task structure of each of these tests also comprises MP facets that can be labeled as dynamic balance (WB), agility (SP), and power (JS, HO).

\section{4 | Data quality control}

Data quality control was assessed in three steps. In step 1 , all physical education teachers were trained by the principal investigator of the study. Step 2 comprised a retesting of 25 children (13 boys; 12 girls) 1 week apart, and the ANOVA-based intraclass correlation coefficient $(R)$ was used to estimate the relative reliability: $R=0.98$ for stature and $0.75 \leq R \leq 0.91$ for GMC tests. In step 3, all data entries were checked for unusual values, outliers, and normality distribution.

\section{5 | Statistical methods}

Descriptive statistics are presented as means and standard deviations. Furthermore, we tested for age-by-sex interactions in each of the GMC tests using an ANOVA model. Additionally, sex differences in GMC mean peak spurts in each test were verified using independent-samples $t$ tests. SPSS 24.0 was used in these analyses, and the level of significance was set at $P<0.05$.

To estimate children's MGS in stature, as well as GMC spurts in each of the four tests aligned by the age of peak MGS, we used the methodology originally designed by Van't Hof, Roede, and Kowalski (1976), which was initially applied to the adolescent growth and MP data of Belgium boys (Beunen, Malina, Van't Hof, Simons, \& Renson, 1988). It was later used with Spanish youth of both sexes (Yaguie, La Fuente, \& Manuel, 1998) as well as with young Belgium soccer players (Philippaerts et al., 2006).

This methodology is valid during the MGS if the following conditions are satisfied: (a) the presence of a real spurt, that is, an increase in velocity, and (b) a specific slowdown of growth velocity after the peak. Additionally, cubic splines were used to smooth the curves. A University Porto mathematician and programmer developed the software to conduct all analysis and graph results.

\section{3 | RESULTS}

Descriptive statistics for height and weight, as well as for all GMC tests, across age groups are summarized in Table 1. As expected, boys and girls became systematically taller and heavier from 6 to 9 years of age. Furthermore, children

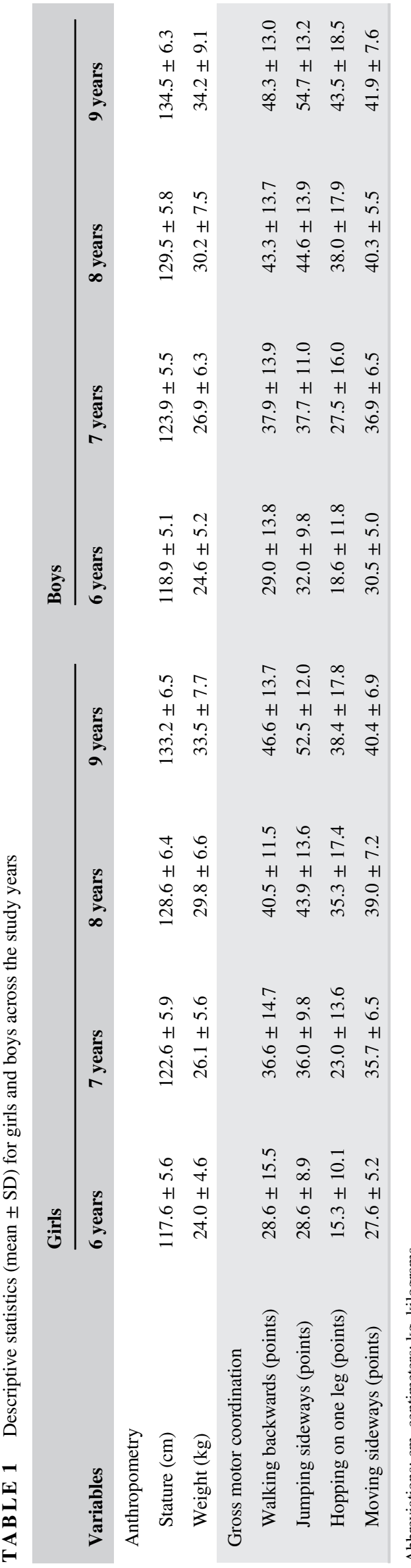


exhibited, on average, increases in all GMC tests with advancing age. However, no statistically significant age-bysex interactions were found for the anthropometric variables (stature, $P=0.06$; weight, $P=0.98$ ) as well as for GMC (WB, $P=0.16$; JS, $P=0.07$; HO, $P=0.09$; SP, $P=0.15$ ).

Smoothed curves were successfully fitted for 170 children ( 82 boys and 88 girls) (Figure 1 and Table 2). In boys, the peak MGS was, on average, at $7.8 \pm 0.47$ years. The minimum velocity was attained at 12 months before the age of peak MGS $\left(4.4 \mathrm{~cm} \cdot \mathrm{yr}^{-1}\right)$ and the maximum was $6.2 \mathrm{~cm} \cdot \mathrm{yr}^{-1}$. Thereafter, the velocity decreased to $4.7 \mathrm{~cm} \cdot$ year $^{-1}$ at 12 months after the age of peak MGS (Figure 1). In girls, the mean age at peak MGS was $8.0 \pm 0.72$ years. Their minimum velocity $\left(4.4 \mathrm{~cm} \cdot \mathrm{yr}^{-1}\right)$ was attained at the same age as in boys. The estimated peak velocity was $6.4 \mathrm{~cm} \cdot \mathrm{yr}^{-1}$, and then velocity decreased to $4.9 \mathrm{~cm} \cdot$ year $^{-1} 12$ months after the age of peak MGS. A marginal significant difference was noticed in boys' and girls' age at peak $(P=0.04)$.

The mean constant velocity GMC curves for each of the four tests are shown in Figure 2, and the mean velocities are summarized in Table 3. In boys, the peak velocity for WB seemed to occur at 18 months before the age of peak MGS (14.9 points. $\left.\mathrm{yr}^{-1}\right)$, whereas in girls this peak occurred

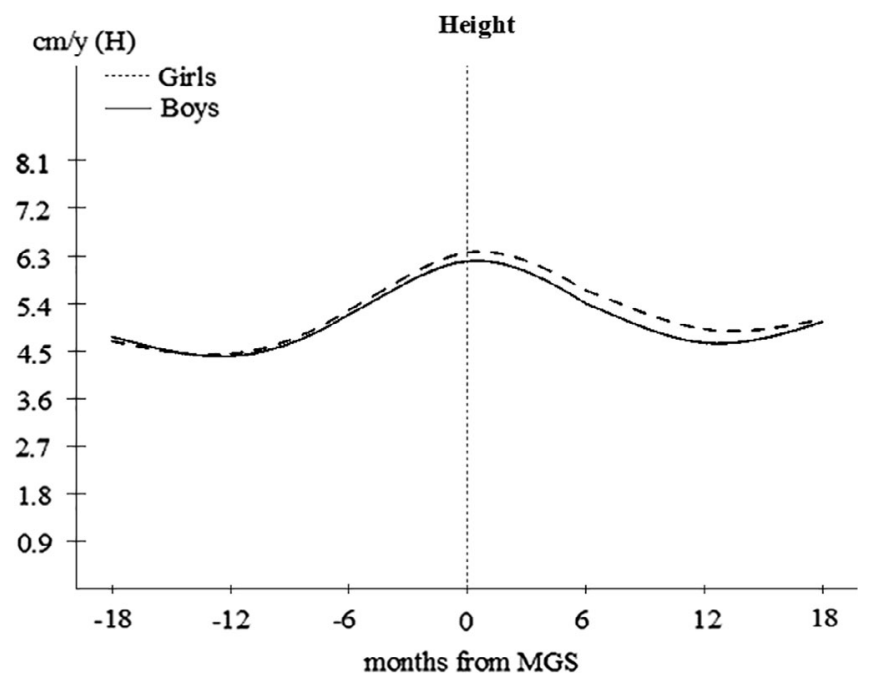

F I G U R E 1 Mean constant velocity curves for height in boys $\left(\right.$ peak MGS $=6.2 \mathrm{~cm} \cdot \mathrm{y}^{-1}$ ) and in girls $\left(\right.$ peak MGS $=6.4 \mathrm{~cm} \cdot \mathrm{y}^{-1}$ )
12 months after the age of peak MGS (13.3 points. $\left.\mathrm{yr}^{-1}\right)$. In boys' JS, the peak was estimated to be 12 months after the age of peak MGS (13.5 points.yr ${ }^{-1}$ ), but in girls, the spurt occurred 12 months before the age of peak MGS (10.5 points $\left.\cdot \mathrm{yr}^{-1}\right)$. Boys' peak spurt in HO was estimated to occur 18 months before the age of peak MGS (11.7 points $\mathrm{yr}^{-1}$ ), while in girls the peak spurt was coincident with the age of peak MGS (10.4 points $\left.\cdot \mathrm{yr}^{-1}\right)$. The corresponding velocities for SP occurred 12 months before the age of peak MGS (6.8 points $\cdot \mathrm{yr}^{-1}$ ) in boys, whereas in girls this velocity was present at 18 as well as 12 months before the age of peak MGS. Figure 3 shows the joint curves, their spurts, and peaks of the four GMC tests in boys and in girls.

No statistically significant differences were observed in the mean peak spurts between boys and girls within each GMC test: WB, $P=0.641$; JS, $P=0.058$; HO, $P=0.632$; or SP, $P=0.738$ ).

\section{4 | DISCUSSION}

An MGS in stature was found between 6 and 8 years of age in the Portuguese children. However, we only identified an MGS in stature in $70 \%$ of the sample, whereas we failed to detect such a spurt in $30 \%(n=65)$. This is probably due to (a) the fact that we only have annual measurements and this may hinder the estimation of individual spurts. Yet, in the First Zürich Longitudinal Growth Study (Gasser, Kneip, Binding, Prader, \& Molinari, 1991), annual measurements were taken from 24 months of age till 9 years in girls and 10 in boys, and this did not impede the precise identification and estimation of the MGS parameters in both boys and girls. (b) The fact that some children may not experience only one MGS, but two or three of low intensity (Butler et al., 1990), or no MGS (Tanner \& Cameron, 1980). In Belgium adolescent soccer players (Philippaerts et al., 2006) and Spanish adolescents (Yagüe et al., 1998), it was also reported that in several cases it was not possible to identify a peak when their MP data were aligned to the age at PHV. In any case, we were successful in aligning children around their growth spurt, similar to the alignment made by Beunen and Malina (1988). To our knowledge, this is the first study

T A B L E 2 Boys and girls mean $( \pm$ SDs) growth velocities for the mid-growth spurt (MGS) in stature

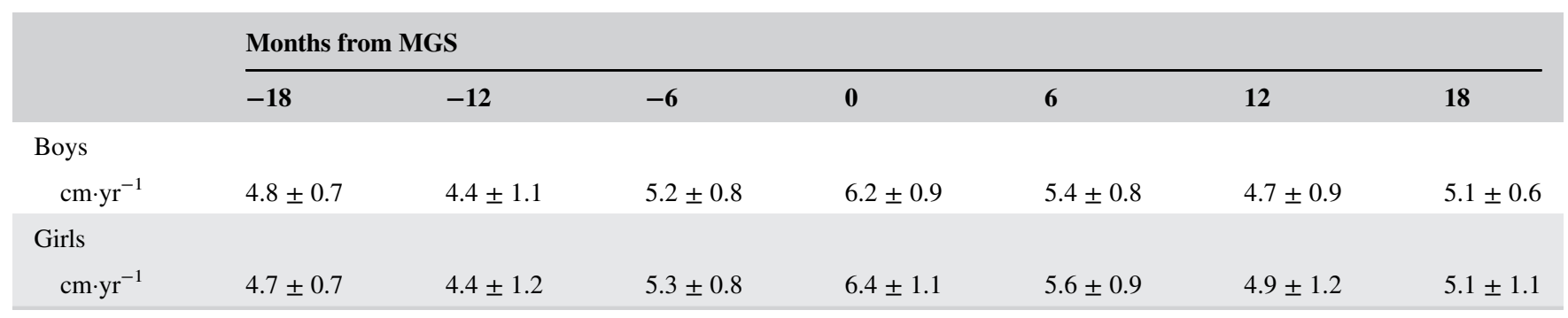

Abbreviation: $\mathrm{cm}^{\mathrm{yr}} \mathrm{r}^{-1}$, centimeters per year. 

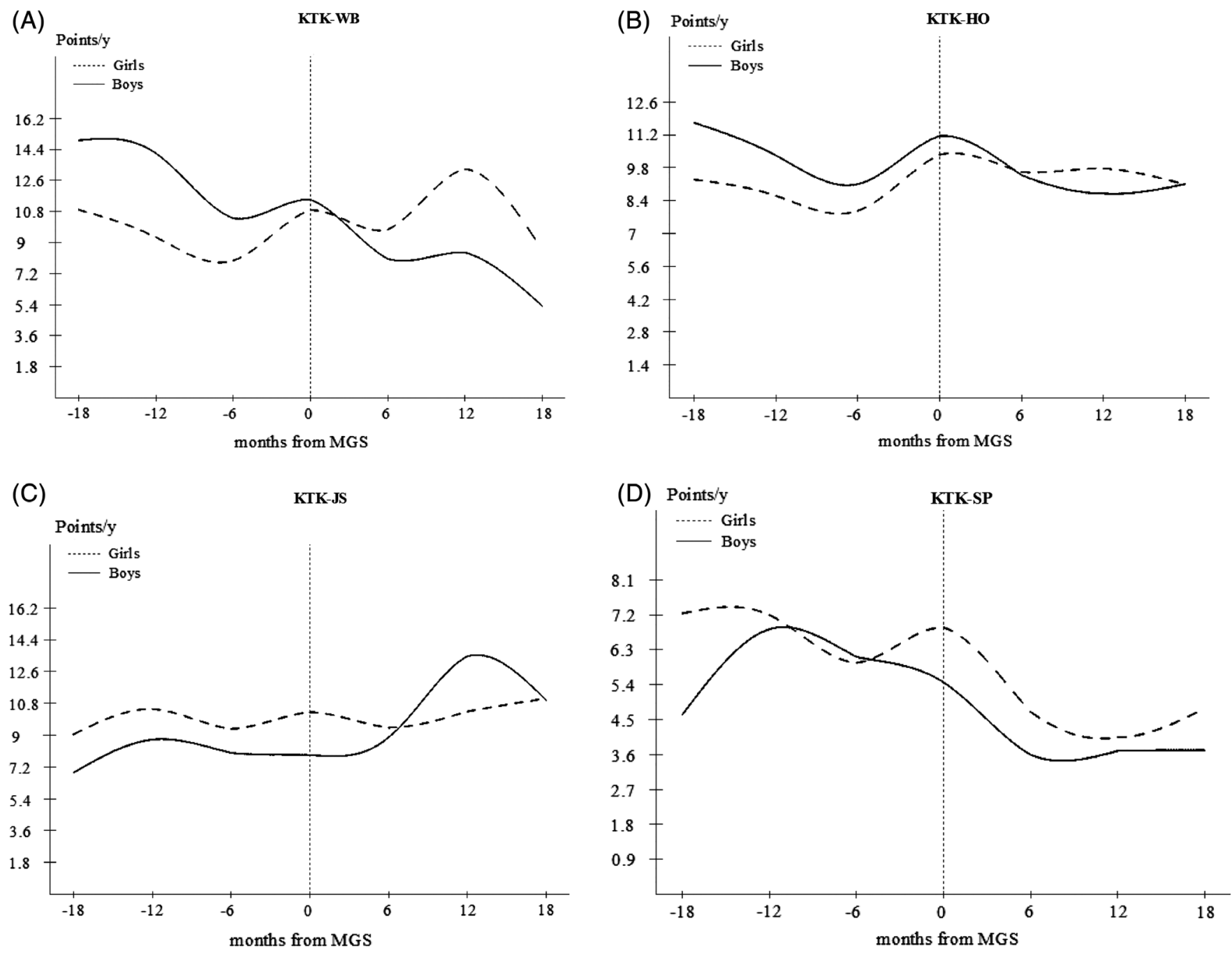

F I G U RE 2 Mean constant velocity curves (points·yr ${ }^{-1}$ ) for KTK-WB (walking backwards), KTK-JS (jumping sideways), KTK-HO (hopping on one leg), and KTK-SP (shifting platforms)

that addresses this issue, showing a series of GMC spurts as well as time differences in peaks between boys and girls.

The timing and tempo of the MGS in stature of the Portuguese children compares closely to previous reports. The age at peak and the intensity of the MGS in stature of the Portuguese boys ( 7.8 years, peak growth $=6.2 \mathrm{~cm} \cdot \mathrm{yr}^{-1}$ ) and girls ( 8.0 years, peak growth $=6.4 \mathrm{~cm} \cdot \mathrm{yr}^{-1}$ ) nearly overlapped the MGS reported by Butler et al. (1990) in Scottish children (boys, 7.0 years, peak $=6.7 \mathrm{~cm} \cdot \mathrm{yr}^{-1}$; girls, 6.7 years, peak $=6.8 \mathrm{~cm} \cdot \mathrm{yr}^{-1}$ ) and by Gasser et al. (1985) in Swiss children (boys, 7.7 years, peak $=6.4 \mathrm{~cm} \cdot \mathrm{yr}^{-1}$; girls, 7.5 years, peak $=6.4 \mathrm{~cm} \cdot \mathrm{yr}^{-1}$ ). The small differences found in the intensity of the MGS may reflect real biological variation or it could be related to sampling procedures, variation in the frequency of measurements, and methods of estimating growth velocities (Malina, Bouchard, \& Bar-Or, 2004). Furthermore, it has been suggested that the occurrence of a MGS is linked to growth hormone pulses, and that thyroid hormone, insulin, cortisol, and adrenal androgens may play central roles in this process (Johnston, 1986). Yet, as Butler et al. (1990) and Sheehy, Gasser, Molinari, and Largo (1999) indicate, care must be taken when linking the temporal association between the mid-childhood spurt and adrenarche.

The second aim of this study was to identify GMC spurts when performance was aligned to the age-at-peak MGS. A spurt was identified in the four GMC tasks showing differences in age within and between boys and girls, but not in their peak intensities. Initial "spurts" in fundamental motor skills and, therefore, in GMC, are perhaps greater than the physical growth spurt because they take place during childhood and not during puberty (Cools, De Martelaer, Samaey, \& Andries, 2009; Martinek, Zaichkowsky, \& Cheffers, 1977).

Children's daily activities, namely those linked to play, sports practice, and general physical activity, are dependent 
T A B L E 3 Boys and girls mean growth velocities for gross motor coordination (GMC) tests aligned on their respective age at mid-growth spurt (MGS) in stature

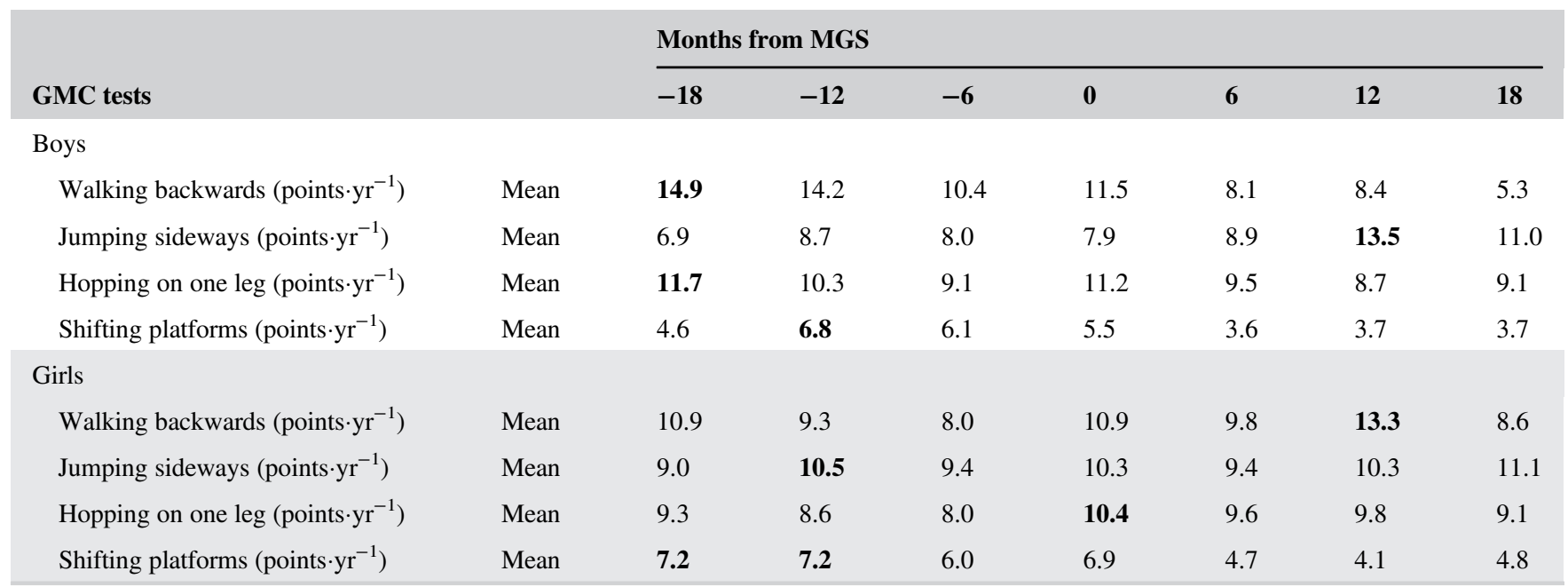

Note: Bold values correspond to peak velocities. Abbreviation: points $\cdot \mathrm{yr}^{-1}$, points per year.
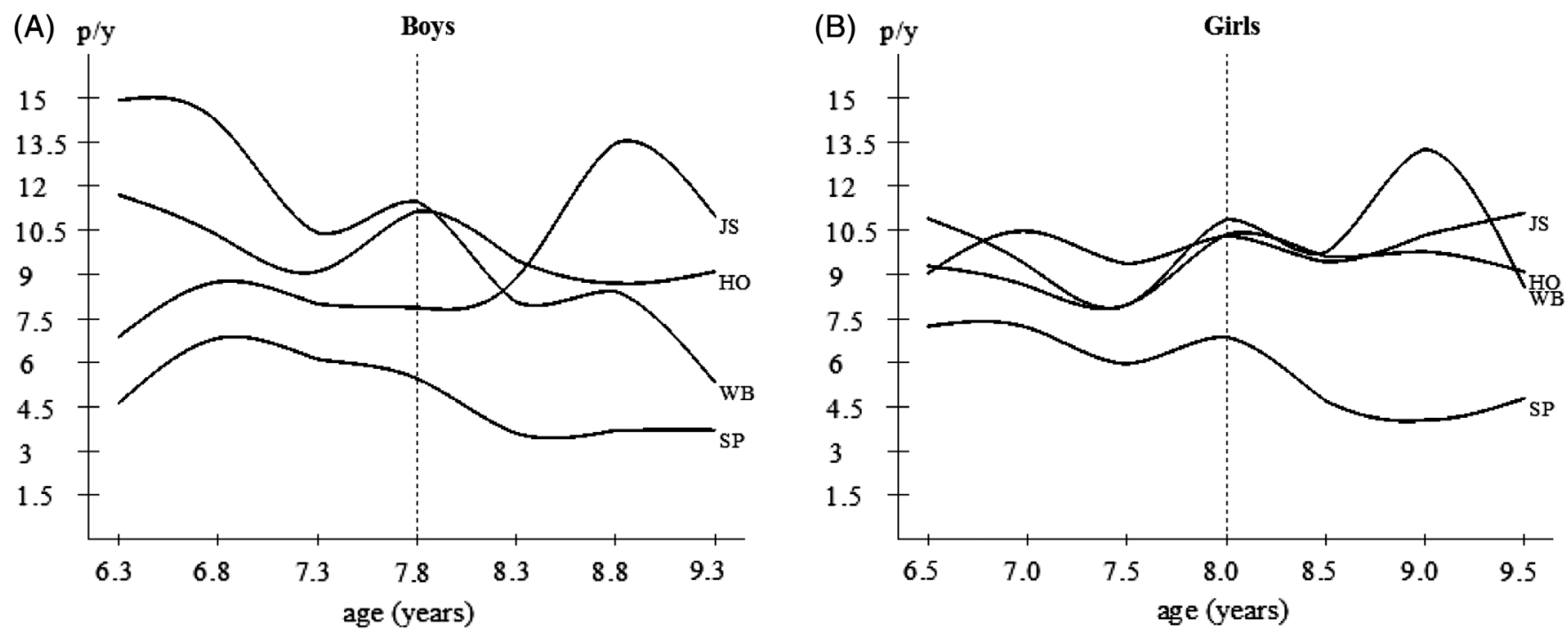

F I G U R E 3 Joint mean constant velocity curves of the four tests in boys and girls. WB, walking backwards; JS, jumping sideways; HO, hopping on one leg; $\mathrm{SP}$, shifting platforms $\left(\mathrm{p} / \mathrm{y}=\right.$ points $\left.\cdot \mathrm{yr}^{-1}\right)$

to some extent on basic components or "factors" such as strength, agility, balance, and flexibility. These factors are also common to most motor skills but vary with the type of motor skill or task (Zaichkowsky, Zaichkowsky, \& Martinek, 1980). For example, in the KTK test battery, the JS test has a structure that mainly expresses velocity in alternate jumping, and the HO test maps the coordination of lower limbs in conjunction with the dynamic strength of these limbs. Our findings showed that in boys, the JS peak spurt occurred at 9.0 years (intensity $=13.5$ points $\cdot \mathrm{yr}^{-1}$ ), that is, after MGS, and the $\mathrm{HO}$ at 6.0 years (intensity $=11.7$ points $\cdot \mathrm{yr}^{-1}$ ), that is, before the MGS. In girls, the JS peak spurt was at 6.8 years before the MGS (intensity $=10.5$ point $\cdot \mathrm{yr}^{-1}$ ), but the
HO was coincident with MGS, that is, 8.0 years (intensity $=10.4$ points $\cdot \mathrm{yr}^{-1}$ ).

For JS and HO, sex differences may be due to the fact that growth in stature is also accompanied by an increase in size attained by specific parts of the body (Butler et al., 1990) and gains in muscular strength that may lead to subsequent increases in MP (Branta, Haubenstricker, \& Seefeldt, 1984; Butler et al., 1990). Additionally, the spurts of the legs and trunk are not synchronous, that is, the maximal velocity is reached, on average, three-quarters of a year later for the trunk than for the legs in girls, whereas in boys it is about a half-a-year later (Gasser et al., 1991), and this may influence the differences found in these motor tests. It is also 
acknowledged that stabilization of locomotor skills is reported at 9.5 and 10.0 years in jumping, and 6.5 and 5.6 years in skipping for boys and girls, respectively (Seefeldt \& Haubenstricker, 1982). Therefore, these stage transitions may also be linked to the GMC spurts.

The other KTK tests refer to dynamic balance (WB) and agility (SP), and showed small differences when their spurts were aligned with the age-at-peak MGS. In WB and SP, the age at peak was at 6.0 years (intensity $=14.9$ points $\cdot \mathrm{yr}^{-1}$ ) and 6.6 years (intensity $=6.8$ points $\cdot \mathrm{yr}^{-1}$ ), that is, before MGS, respectively, in boys; in girls it was at 9.2 years (intensity $=13.3$ point $\cdot \mathrm{yr}^{-1}$ ) after MGS and 6.2 and 6.8 years (intensity $=7.2$ points $\cdot \mathrm{yr}^{-1}$ ) before MGS, respectively. Motor tasks that involve balance are critical to daily movement behaviors and are influenced by visual, tactile kinesthetic, and visual stimulation (Humphriss, Hall, May, \& Macleod, 2011). The execution of WB and SP tasks is based on the integration of proprioception, vestibular function, and vision that are necessary to maintain the control of the body in movements that requires synergetic functioning of the cerebellum, spinal cord, and skeletal muscle innervation (Achiron \& Kalron, 2008). On the other hand, it is likely that neurological maturation (ie, girls have a "slightly" advanced neurological development) and variations in children's information processing capacity, as well as environmental characteristics and the task itself, need to be considered in explaining potential differences in these motor tests (Caçola, Ibana, Ricard, \& Gabbard, 2016).

This study is not without limitations, and we point out at least two. First, we only have assessments of GMC at yearly intervals. It is possible that using half-year assessments will be more accurate in the estimation of GMC spurts. However, over short intervals of assessment a learning effect in performing each task could occur, which makes it difficult to distinguish between the test-retest effects and the true change. Additionally, starting the study at 5 years of age would also probably contribute to the preciseness of the parameter estimates as well as the GMC spurts. Second, some care should be taken when generalizing our findings to other groups of children. On the other hand, this study is unique in the sense that the identification of MGSs in GMC is novel. Our sample is also larger than previous studies and the method used to derive the velocity curve seems to fit well the MGS of the GMC tasks. The KTK test battery is also a valid marker of the GMC given the extensive research published in recent years.

In conclusion, boys and girls reached their MGS in stature at about the same chronological age. Spurts in GMC did not express themselves in the same biological timing relative to age at MGS in height, and there are sex differences in the timing. This information is useful and will most certainly help physical education teachers, parents, and sports' coaches to better understand children's GMC and use these putative sensitive periods, that is, GMC spurts, to enhance the efficiency of their educational programs.

\section{ACKNOWLEDGMENTS}

The authors would like to thank the physical education teachers, children, and parents for their participation in the study across the years.

This paper was written in honor of the late Professor Gaston Beunen and his insights into gross motor coordination spurts.

\section{CONFLICT OF INTERESTS}

Marcos André Moura dos Santos, Adam Baxter-Jones, Ana Carolina Reyes, Duarte Freitas, Rafael S. Henrique, Raquel Nichele Chaves, Alcibíades Bustamante, Go Tani, Peter T Katzmarzyk, and José Maia declare that they have no conflict of interest.

\section{INFORMED CONSENT}

Informed consent was obtained from all individual participants included in the study.

\section{AUTHOR CONTRIBUTIONS}

J.M. designed and directed the study as well as the data collection. M.A.M.S., J.M., A.B.J., D.F., G.T., and R.N.C. conceptualized the article. A.B., R.H.S., and A.C.R. prepare the data set, cleaned it, and did the first analyses. M.A.M.S., A.B.J., P.T.K., and J.M. drafted the manuscript; R.S.H., R.N.C., G.T., D.F., P.T.K., and A.B. provided critical comments and helped in the final version.

\section{ORCID}

Marcos A. M. dos Santos (10 https://orcid.org/0000-00022734-8416

Rafael S. Henrique (10 https://orcid.org/0000-0003-39125559

\section{REFERENCES}

Achiron, A., \& Kalron, A. (2008). Physical activity: Positive impact on brain plasticity. Harefuah, 147(3), 252-255 276.

Antunes, A. M., Maia, J. A., Gouveia, É. R., Thomis, M. A., Lefevre, J. A., Teixeira, A. Q., \& Freitas, D. L. (2016). Change, stability and prediction of gross motor co-ordination in Portuguese children. Annals of Human Biology, 43(3), 201-211.

Barnett, L. M., Lai, S. K., Veldman, S. L., Hardy, L. L., Cliff, D. P., Morgan, P. J., ... Ridgers, N. D. (2016). Correlates of gross motor 
competence in children and adolescents: A systematic review and meta-analysis. Sports Medicine, 46(11), 1663-1688. https://doi.org/ 10.1007/s40279-016-0495-z

Beunen, G., \& Malina, R. M. (1988). Growth and physical performance relative to the timing of the adolescent spurt. Exercise and Sport Sciences Reviews, 16, 503-541.

Beunen, G. P., Malina, R. M., Van't Hof, M. A., Simons, J., Ostyn, M., \& Renson, V. G. D. (1988). Adolescent growth and motor performance: A longitudinal study of Belgian boys (Vol. 1). Champaign, IL: Human Kinetics.

Branta, C., Haubenstricker, J., \& Seefeldt, V. (1984). Age changes in motor skills during childhood and adolescence. Exercise and Sport Sciences Reviews, 12, 467-520.

Butler, G. E., McKie, M., \& Ratcliffe, S. G. (1990). The cyclical nature of prepubertal growth. Annals of Human Biology, 17(3), 177-198.

Caçola, P., Ibana, M., Ricard, M., \& Gabbard, C. (2016). Children with developmental coordination disorder demonstrate a spatial mismatch when estimating coincident-timing ability with tools. Research in Developmental Disabilities, 48, 124-131.

Chaves, R., Baxter-Jones, A., Gomes, T., Souza, M., Pereira, S., \& Maia, J. (2015). Effects of individual and school-level characteristics on a child's gross motor coordination development. International Journal of Environmental Research and Public Health, 12(8), 8883-8896.

Cools, W., De Martelaer, K., Samaey, C., \& Andries, C. (2009). Movement skill assessment of typically developing preschool children: A review of seven movement skill assessment tools. Journal of Sports Science \& Medicine, 8(2), 154-168.

Gallahue, D., Ozmun, J., \& Goodway, J. (2012). In D. Patterson (Ed.), Understanding motor development: Infants, children, adolescents, adults. New York: McGraw-Hill International Edition.

Gasser, T., Kneip, A., Binding, A., Prader, A., \& Molinari, L. (1991). The dynamics of linear growth in distance, velocity and acceleration. Annals of Human Biology, 18(3), 187-205.

Gasser, T., Müller, H.-G., Köhler, W., Prader, A., Largo, R., \& Molinari, L. (1985). An analysis of the mid-growth and adolescent spurts of height based on acceleration. Annals of Human Biology, 12(2), 129-148.

Gasser, T., Sheehy, A., Molinari, L., \& Largo, R. (2001). Growth of early and late maturers. Annals of Human Biology, 28(3), 328-336.

Gorla, J. I., de Araújo, P. F., \& Rodrigues, J. L. (2010). Avaliação motora em educação física: Teste KTK. In São Paulo (1 Ed.), Phorte Editora LTDA.

Hauspie, R., \& Roelants, M. (2012). Adolescent growth. In N. Cameron \& B. Bogin (Eds.), Human growth and development. London: Academic Press.

Humphriss, R., Hall, A., May, M., \& Macleod, J. (2011). Balance ability of 7 and 10 year old children in the population: Results from a large UKbirth cohort study. International Journal of Pediatric Otorhinolaryngology, 75(1), 106-113.

Johnston, F. E. (1986). Somatic growth of the infant and preschool child. In Postnatal growth neurobiology (pp. 3-24). Boston, MA: Springer.

Lejarraga, H. (2012). Growth in infancy and childhood: A pediatric approach. In C. Noël \& B. Barry (Eds.), Human growth and development. London: Academic Press.

Lohman, T. G., Roche, A. F., \& Martorell, R. (1988). Anthropometric standardization reference manual. Champaign, IL: Human kinetics books.
Maia, J. A., Lopes, V. P., Silvas, R. G. D., Seabra, A., Fonseca, A. M., Bustamante, A., ... Cardoso, M. (2007). Crescimento e desenvolvimento de crianças e jovens açorianos. O que os pais, professores, pediatras e nutricionistas gostariam saber. DREFD-RAA \& FCDEF-UP. Porto.

Malina, R. M., Bouchard, C., \& Bar-Or, O. (2004). Growth, maturation, and physical activity. Champaign, IL: Human Kinetics.

Martinek, T. J., Zaichkowsky, L. D., \& Cheffers, J. T. F. (1977). Decision-making in elementary age children: Effects on motor skills and self-concept. Research Quarterly. American Alliance for Health, Physical Education and Recreation, 48(2), 349-357. https://doi. org/10.1080/10671315.1977.10615432

Molinari, L., Largo, R., \& Prader, A. (1980). Analysis of the growth spurt at age seven (mid-growth spurt). Helvetica Paediatrica Acta, 35(4), 325-334.

Mühl, A., Herkner, K., \& Swoboda, W. (1992). The mid-growth spurt--a pre-puberty growth spurt. Review of its significance and biological correlations. Padiatrie Und Padologie, 27(5), 119-123.

Philippaerts, R. M., Vaeyens, R., Janssens, M., Van Renterghem, B., Matthys, D., Craen, R., ... Malina, R. M. (2006). The relationship between peak height velocity and physical performance in youth soccer players. Journal of Sports Sciences, 24(3), 221-230.

Robinson, L. E., Stodden, D. F., Barnett, L. M., Lopes, V. P., Logan, S. W., Rodrigues, L. P., \& D'Hondt, E. (2015). Motor competence and its effect on positive developmental trajectories of health. Sports Medicine, 45(9), 1273-1284.

Schilling, F., \& Kiphard, E. J. (1974). Körperkoordinationstest für Kinder: KTK. Göttingen: Beltz.

Seefeldt, V., \& Haubenstricker, J. (1982). Patterns, phases, or stages: An analytical model for the study of developmental movement. The Development of Movement Control and Coordination, 309, 318.

Sheehy, A., Gasser, T., Molinari, L., \& Largo, R. (1999). An analysis of variance of the pubertal and midgrowth spurts for length and width. Annals of Human Biology, 26(4), 309-331.

Stodden, D. F., Goodway, J. D., Langendorfer, S. J., Roberton, M. A., Rudisill, M. E., Garcia, C., \& Garcia, L. E. (2008). A developmental perspective on the role of motor skill competence in physical activity: An emergent relationship. Quest, 60(2), 290-306. https:// doi.org/10.1080/00336297.2008.10483582

Tanner, J., \& Cameron, N. (1980). Investigation of the mid-growth spurt in height, weight and limb circumferences in single-year velocity data from the London 1966-67 growth survey. Annals of Human Biology, 7(6), 565-577.

Tchamo, M. E., Moura-dos-Santos, M. A., dos Santos, F. K., Prista, A., \& Leandro, C. G. (2017). Deficits in anthropometric indices of nutritional status and motor performance among low birth weight children from Maputo City, Mozambique. American Journal of Human Biology, 29(3), 1-9.

Valdivia, A. B., Cartagena, L. C., Sarria, N. E., Távara, I. S., Teixeira, A. F., da Silva, R. M. G., \& Maia, J. A. R. (2008). Motor coordination: Influence of age, sex, socio-economic status and levels of adiposity, in Peruvian children. Brazilian Journal of Kinanthropometry and Human Performance, 10(1), 25-34.

Valdivia, A. B., Lara, R. F., Espinoza, C. B., Pomahuacre, S. Q., Ramos, G. R., Seabra, A., ... Maia, J. (2008). Prontitud coordinativa: perfiles multivariados en función de la edad, sexo y estatus socio-económico. Revista Portuguesa de Ciências Do Desporto, 8(1), 34-46. 
Van't Hof, M. A., Roede, M. J., \& Kowalski, C. J. (1976). Estimation of growth velocities from individual longitudinal data. Growth, 40 , 217-240.

Vandorpe, B., Vandendriessche, J., Lefèvre, J., Pion, J., Vaeyens, R., Matthys, S., ... Lenoir, M. (2011). The Körperkoordinationstest für kinder: Reference values and suitability for 6-12-year-old children in Flanders. Scandinavian Journal of Medicine \& Science in Sports, 21(3), 378-388.

Willimczik, K. (1980). Development of motor control capability (body coordination) of 6-to 10-year-old children: Results of a longitudinal study. Baltimore, MD: University Park Press.

Yagüe, P. H., La Fuente, D., \& Manuel, J. (1998). Changes in height and motor performance relative to peak height velocity: A mixed- longitudinal study of Spanish boys and girls. American Journal of Human Biology, 10(5), 647-660.

Zaichkowsky, L. D., Zaichkowsky, L. B., \& Martinek, T. J. (1980). Growth and development: The child and physical activity. St. Louis: Mosby.

How to cite this article: dos Santos MAM, BaxterJones A, Reyes AC, et al. Are there gross motor coordination spurts during mid-childhood? Am J Hum Biol. 2019;31:e23251. https://doi.org/10.1002/ajhb. 23251 